\title{
Comparative study of nanohydroxyapatite microspheres for medical applications
}

\author{
Alis Yovana Pataquiva Mateus, ${ }^{1,2}$ Cristina C. Barrias, ${ }^{1}$ Cristina Ribeiro, ${ }^{1,3}$ Maria P. Ferraz, ${ }^{1,4}$ \\ Fernando J. Monteiro, ${ }^{1,2}$ \\ ${ }^{1}$ INEB-Instituto de Engenharia Biomédica, Laboratório de Biomateriais, Rua do Campo Alegre 823, \\ 4150-180 Porto, Portugal \\ ${ }^{2}$ Departamento de Engenharia Metalúrgica e Materiais, Faculdade de Engenharia, Universidade do Porto, \\ Porto, Portugal \\ ${ }^{3}$ Instituto Superior de Engenharia do Porto, Rua Dr. António Bernardino de Almeida 431, 4200-072 Porto, Portugal \\ ${ }^{4}$ Universidade Fernando Pessoa, Praça 9 de Abril 349, 4249-004 Porto, Portugal
}

Received 21 February 2006; revised 2 April 2007; accepted 6 July 2007

Published online 1 November 2007 in Wiley InterScience (www.interscience.wiley.com). DOI: 10.1002/jbm.a.31634

\begin{abstract}
This study concerns the preparation, physical, and in vitro characterization of two different types of hydroxyapatite (HA) microspheres, which are intended to be used as drug-delivery systems and bone-regeneration matrices. Hydroxyapatite nanoparticles (HA-1 and HA-2) were prepared using the chemical precipitation synthesis with $\mathrm{H}_{3} \mathrm{PO}_{4}, \mathrm{Ca}(\mathrm{OH})_{2}$, and a surfactant, SDS (sodium dodecyl sulfate), as starting reagents. The HA powders were dispersed in a sodium alginate solution, and spherical particles were obtained by droplet extrusion coupled with ionotropic gelation in the presence of $\mathrm{Ca}^{2+}$. These were subsequently sintered to produce HA-1 and HA-2 microspheres with a uniform size and interconnected microporosity. Both powders and microspheres were characterized using FTIR and X-ray diffraction. Moreover, SEM and mercury intrusion porosimetry were used to analyze the
\end{abstract}

microspheres, and TEM was used to analyze the powders. Results showed that pure HA and mixtures of HA/ $\beta$-TCP in the nanometer range and needlelike shape were obtained for HA-1 and HA-2 powders, respectively. Neutral Red, scanning electron microscopy and confocal microscopy were used to evaluate the behavior of osteoblastic-like MG-63 cells cultured on HA microspheres surfaces for 7 days. Results showed that good adhesion and proliferation of osteoblasts on the HA microspheres surface. Cells built bridges between adjacent microspheres, forming microspheres-cells clusters in both types of materials. (C) 2007 Wiley Periodicals, Inc. J Biomed Mater Res 86A: 483-493, 2008

Key words: hydroxyapatite; nanoparticles; microspheres; osteoblasts; bone regeneration

\section{INTRODUCTION}

Many biomaterials have been studied to repair bone defects or restore bone tissue functionality. During the last two decades, extensive research on ceramic materials, like calcium phosphates, has shown that these materials are suitable as bone substitutes due to their biocompatible, bioactive, biodegradable, and osteoconductive characteristics, ${ }^{1-5}$ and when implanted in vivo, they are nontoxic and do not induce any antigenic response. ${ }^{6}$

Correspondence to: A. Y. P. Mateus; e-mail: yovana@ibmc. up.pt or alis@fe.up.pt

Contract grant sponsor: Portuguese Foundation for Science and Technology; contract grant number: POCTI/ FCB/41523/2001

(C) 2007 Wiley Periodicals, Inc.
Bone exhibits natural hydroxyapatite (HA) crystals with needlelike or rodlike shapes, well arranged within the polymeric matrix of collagen type I. These natural nanoparticles formed in physiological environment have a more dynamic response when compared with synthetic material with larger particle size. ${ }^{7}$ To prepare fine HA powders, many chemical processing routes have been employed, including hydrothermal reactions, ${ }^{8-10}$ sol-gel synthesis, ${ }^{11-13}$ pyrolysis of aerosols, ${ }^{14,15}$ and microemulsion, ${ }^{16,17}$ biomimetic process, ${ }^{18,19}$ and chemical precipitation, ${ }^{20-24}$ which is the most used alternative.

Recently, sodium alginate has been presented as an interesting material for biomedical applications, showing capability to be processed under mild conditions. ${ }^{25-28}$ Alginate, seaweed extract composed of chains of alternating $\alpha$-L-guluronic acid and $\beta$-Dmannuronic acid residues, is considered by far the most widely used polymer for immobilization and 
microencapsulation technologies. Sodium alginate is water soluble and may polymerize into a solid matrix. Its processing into microspheres is compatible with the presence of proteins and even bacteria or viruses. Alginate microspheres are an inexpensive, reliable and available agent for antigens encapsulation for example in several animal diseases treatment. Besides, alginate microspheres are stable at low $\mathrm{pH}$ and can be prepared to a wide variety of sizes. ${ }^{29}$ The simple and versatile aqueous-based gel formation of sodium alginate in the presence of divalent cations such as calcium has been used to immobilize cells ${ }^{30}$ for hybrid artificial organs, ${ }^{31}$ hemoglobin carriers, ${ }^{32}$ macromolecular delivery, ${ }^{33-35}$ and drug-delivery systems. ${ }^{35}$

This work describes the preparation and initial characterization of novel HA microspheres intended to be used as a biomaterial for bone regeneration or as enzyme-delivery matrices. The purpose of this work is to do the morphological, chemical composition characterization, and in vitro study of microspheres based on synthesized nanophased HA obtained by two different procedures.

\section{MATERIALS AND METHODS}

\section{Synthesis of nanosized hydroxyapatite}

Aqueous solutions of calcium hydroxide $\left(\mathrm{Ca}(\mathrm{OH})_{2}\right)$ and ortho-phosphoric acid $\left(\mathrm{H}_{3} \mathrm{PO}_{4}, 85 \%\right)$, both of analytical grade, were used as reactants for the preparation of two different types of HA nanoparticles. HA powder 1 (HA-1) was synthesized according to the following procedure: first, $1 \mathrm{~L}$ of an aqueous suspension of $\mathrm{H}_{3} \mathrm{PO}_{4}(0.6 \mathrm{M})$ was slowly added drop by drop to a $1 \mathrm{~L}$ of an aqueous suspension of $\mathrm{Ca}(\mathrm{OH})_{2}(1 \mathrm{M})$ while stirring vigorously for about $2 \mathrm{~h}$ at room temperature. Concentrated $\mathrm{NaOH}$ was added until a final $\mathrm{pH}$ of 10.5 was obtained. The white solution obtained was washed using deionized water and dried in oven at $80^{\circ} \mathrm{C}$ for $24 \mathrm{~h}$. HA powder 2 (HA-2) was synthesized in the same way, with the difference of the addition of sodium dodecylsulfate addition (10 g) into the calcium solution.

\section{Preparation of HA microspheres}

Microspheres were prepared using a methodology previously described. ${ }^{32,34}$ Briefly, pharmaceutical-grade sodium alginate (Protanal 10/60 LS) with a high $\alpha$-L-guluronic acid content $(65-75 \%)$ was kindly donated by Pronova Biopolymers and used without further purification. About $1.5 \mathrm{~g}$ of Na-alginate was dissolved in $50 \mathrm{~mL}$ of distilled and deionized water until total homogenization, where upon nanophased HA powder was added to the alginate solution in a ratio of 2:8 w/w until thorough dispersion. This paste was extruded using a droplet generator device (Encapsulation Unit Var 1-J1, Nisco) into a $0.1 \mathrm{M} \mathrm{CaCl} \mathrm{C}_{2}$ crosslinking solution, wherein spherical-shaped particles were instantaneously formed, and allowed to harden for $30 \mathrm{~min}$. The size of the microspheres was controlled by regulating the extrusion flow rate using a single-syringe infusion pump (EW 47-900-00, Cole Palmer) and by applying a coaxial air stream. The extrusion flow rate for HA-1 was twofold the flow rate for sample HA-2. At the completion of the gelling period, microspheres were recovered and rinsed in water to remove the excess $\mathrm{CaCl}_{2}$. Finally, they were dried overnight in a vacuum oven at $30^{\circ} \mathrm{C}$ and sintered at $1100^{\circ} \mathrm{C}$ for $1 \mathrm{~h}^{36}$

\section{Characterization of nanosized HA}

\section{Infrared spectroscopy}

Chemical characterization was performed using Fourier transformed infrared (FTIR) spectroscopy. For this purpose, HA was reduced to powder and analyzed as $\mathrm{KBr}$ pellets using a PerkinElmer System 2000 spectrometer.

\section{Transmission electron microscopy}

The size and morphology of the HA powders were determined using a transmission electron microscope (TEM, Zeiss model EM 902A) at an accelerating voltage of $80 \mathrm{kV}$. A HA solution was prepared by dispersing $0.5 \mathrm{mg}$ of HA in $1 \mathrm{~mL}$ of ethanol. This was placed in an ultrasonic bath overnight to ensure thorough dispersion. A drop of the solution, agitated for $1 \mathrm{~min}$ in vortex, was placed on a Formvar carbon-coated copper 400 grid and left for $1 \mathrm{~min}$. Excess liquid was removed with filter paper, and the grid was allowed to dry for $10 \mathrm{~min}$. TEM images were acquired and observed with Axion Camera Zeiss and AxionCs 40AC Zeiss, v 4.2.0.0 software.

\section{X-ray diffractometry}

X-ray diffraction (XRD) characterization of HA-1 and HA-2 powders was conducted using a Panalytical X'Pert PRO alpha-1 with a RTMS X'Celerator detector. It used $\mathrm{Ni}$-filtered $\mathrm{Cu} \mathrm{K} \alpha$ radiation over the $2 \theta$ range of $10^{\circ}-90^{\circ}$ at a scan rate of $2.4^{\circ} / \mathrm{min}$ and with a sampling interval of $0.002^{\circ}$ at $40 \mathrm{~mA}$ and $45 \mathrm{kV}$.

\section{Characterization of nano-HA microspheres}

Inverted stand optical microscope analysis

The size of the microspheres was estimated using an inverted stage microscope (Olympus PME3-ADL) with an eye piece lens equipped with an micrometer rule, with an accuracy of $10 \mu \mathrm{m}$. The average diameter was determined from 20 microspheres for each material. 


\section{Infrared spectroscopy}

Chemical characterization was performed using FTIR spectroscopy. For this purpose, nanoHA microspheres were reduced to powder and analyzed as $\mathrm{KBr}$ pellets using a PerkinElmer System 2000 spectrometer.

\section{Scanning electron microscopy analysis}

The microspheres morphology was analyzed by digital imaging and scanning electron microscopy (SEM). Using a JEOL JFC-100 fine coat ion sputter device, samples were sputter coated with gold. Then, they were studied with a JEOL JSM-6301F microscope at an accelerating voltage of $5 \mathrm{kV}$.

\section{Mercury porosimetry method}

Mercury intrusion porosimetry equipment (Quantachrome Poremaster model No. 60) was used to determine the surface area, pore number fraction, and porosity from both types of microspheres. Samples were dried at room temperature; about $1.8 \mathrm{~g}$ dried microspheres were used in this determination and Helium was used for gas adsorption. The data reported were obtained using Quantachrome Poremaster for Windows, version 3.0.

\section{X-ray diffractometry}

X-ray diffraction (XRD) characterization of HA microspheres was conducted using a Panalytical X'Pert PRO alpha-1 with a RTMS X'Celerator detector. It used Nifiltered $\mathrm{Cu} \mathrm{K} \alpha$ radiation over the $2 \theta$ range of $10^{\circ}-90^{\circ}$ at a scan rate of $2.4^{\circ} / \mathrm{min}$ and with a sampling interval of $0.002^{\circ}$ at $40 \mathrm{~mA}$ and $45 \mathrm{kV}$.

\section{Biological assessment}

MG-63 cells were cultured at $37^{\circ} \mathrm{C}$ in a humidified atmosphere of $5 \% \mathrm{CO}_{2}$ in air, $\alpha$-MEM (GIBCO 22561-021), $10 \%$ fetal bovine serum (FBS), $1 \%$ fungizone, and $0.5 \%$ gentamicin. For the subculture, the cell monolayer was washed twice with phosphate-buffered saline and incubated with trypsin-EDTA solution $(0.05 \%$ trypsin, $0.25 \%$ EDTA) for $5 \mathrm{~min}$ at $37^{\circ} \mathrm{C}$ to detach the cells. Cells were resuspended in culture medium for reseeding. Microspheres were sterilized at $120^{\circ} \mathrm{C}$ for $20 \mathrm{~min}$, placed on a 96 PS culture plate (14 mg of microspheres in each well, ca. $1 \mathrm{~cm}^{2}$ of surface area), and incubated with PBS overnight. Cells were then seeded on microspheres preconditioned with $\alpha$-MEM with $10 \%$ FBS, $1 \%$ fungizone, and $0.5 \%$ gentamicin. MG-63 cells were cultured $\left(2 \times 10^{4}\right.$ cells $\left./ \mathrm{cm}^{2}\right)$ up to 7 days under controlled conditions (cells seeded on 96 TCPS plates) and on the surface of both type of microspheres. The control cultures and seeded microspheres were evaluated throughout the incubation time (7 days) for cytotoxicity (Neutral Red) and observed by confocal microscopy (CSLM) and SEM. Medium was substituted by fresh one every other day.

\section{Cytotoxicity tests (Neutral Red)}

Cytotoxicity of HA-1 and HA-2 microspheres was investigated on MG-63 osteoblast-like cells, which express a number of features characteristic of relatively immature osteoblasts $^{34}$ using Neutral Red assay. A $0.4 \% \mathrm{w} / \mathrm{v}$ solution of neutral red dye tested for cell cultures (Color Index 50040) in distilled water was prepared and stored at $4^{\circ} \mathrm{C}$ (stock solution). The working solution was prepared immediately before use by diluting the stock solution in complete medium to yield a final concentration of $50 \mu \mathrm{g} / \mathrm{mL}$. Five replicates were performed for each type of microspheres. The negative control was microspheres in culture medium in PS 96 wells culture plates. The positive control was MG-63 in culture medium in 96 wells TCPS culture plates. After incubation for $1,3,5$, and 7 days at $37^{\circ} \mathrm{C}$, the supernatant was discarded, and $0.150 \mathrm{~mL}$ of neutral red dye solution was added to the wells for $3 \mathrm{~h}$ at $37^{\circ} \mathrm{C}$. The supernatant was removed, the wells washed twice with PBS, and $0.1 \mathrm{~mL}$ of lysing solution (50\% ethanol in $1 \%$ acetic acid) was added. The color intensity of each well was read at $540 \mathrm{~nm}$ with reference to $620 \mathrm{~nm}$, the optical densities of the replicates were averaged, and the viability read in negative control was discounted.

\section{Cell morphology (SEM and CLSM)}

For SEM, microspheres-cells constructs were washed twice with PBS and fixed with $1.5 \%$ glutaraldehyde in $0.14 \%$ cacodylate solution for $30 \mathrm{~min}$ at room temperature. They were dehydrated by suspending in successive ethanol solutions (50, 70, 80, 90, and 100\%) for $10 \mathrm{~min}$ in each solution. After dehydration, the samples were transferred to hexamethyldisilazane and air dried at room temperature overnight. Finally, the microspheres-cells constructs were sputter coated with gold and examined under a JEOL JSM-6301F microscope at an accelerating voltage of $5 \mathrm{kV}$.

For CSLM, samples were washed twice with PBS, fixed in $4 \% \mathrm{v} / \mathrm{v}$ formaldehyde (methanol-free; Polyscience) for $15 \mathrm{~min}$, permeabilized with $0.1 \% \mathrm{v} / \mathrm{v}$ Triton X-100 for $5 \mathrm{~min}$, and incubated in $10 \mathrm{mg} / \mathrm{mL}$ bovine serum albumin and $100 \mu \mathrm{g} / \mathrm{mL}$ RNAse for $1 \mathrm{~h}$ at room temperature. Factin filaments were stained with Alexafluor-conjugated phalloidin (Molecular Probes) for $20 \mathrm{~min}$ at RT in dark, and nuclei were counterstained with $10 \mu \mathrm{g} / \mathrm{mL}$ propidium iodide (Sigma) for $15 \mathrm{~min}$. Finally, samples were washed with PBS, mounted in Vectashield ${ }^{\circledR}$, and stored at $4^{\circ} \mathrm{C}$ in dark. CLSM images were acquired on a BioRad MRC 600 microscope.

\section{RESULTS}

The FTIR spectra of powders and microspheres using HA-1 and HA-2 materials are represented in Figure 1. It may be seen that the crystallinity 

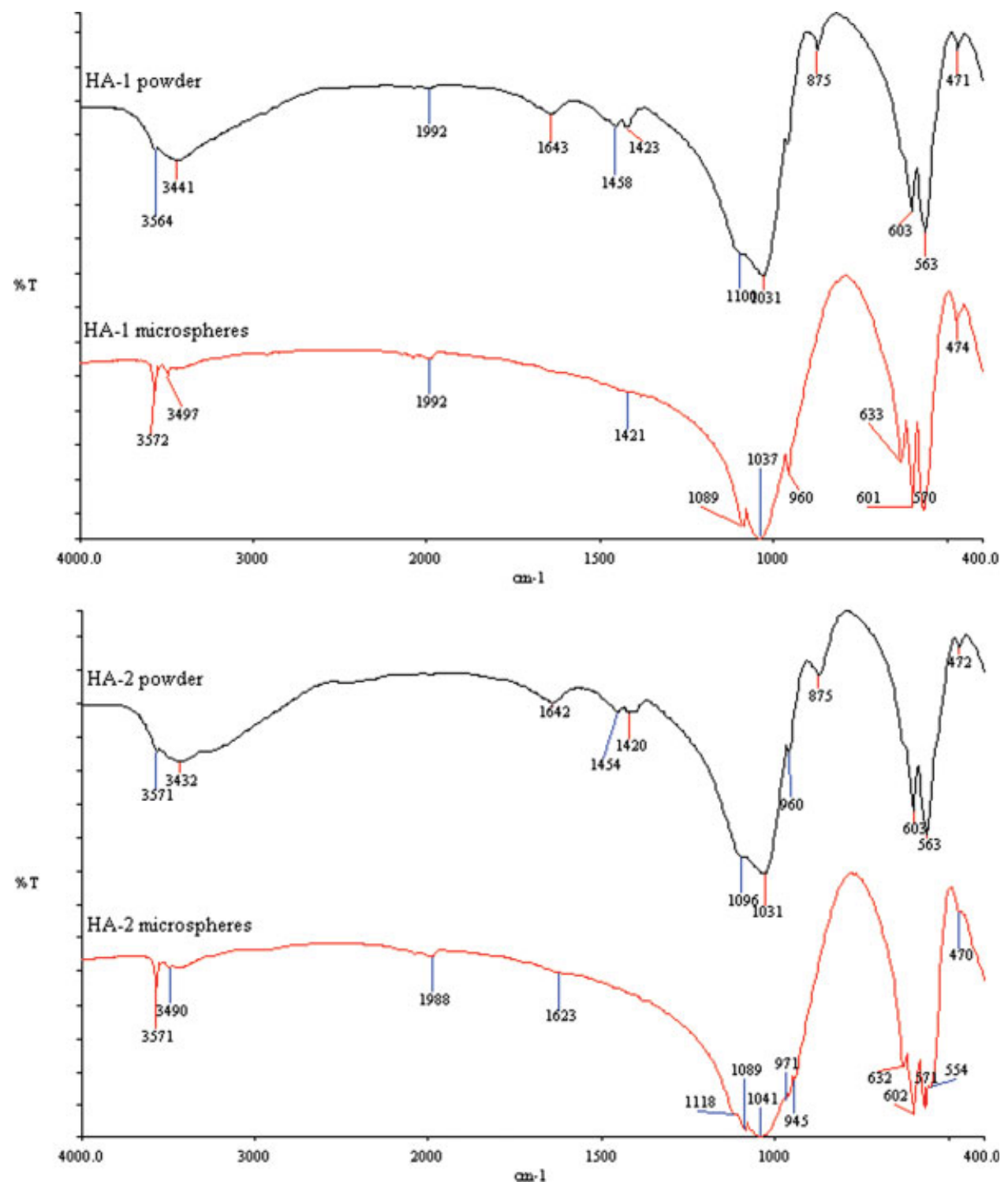

Figure 1. FTIR spectra of HA-1 and HA-2 samples (powders and microspheres). [Color figure can be viewed in the online issue, which is available at www.interscience.wiley.com.]

increased from HA-1 powder to HA-1 microspheres, especially on the phosphate bands at $560-633 \mathrm{~cm}^{-1}$ and around $1030 \mathrm{~cm}^{-1}$. Occluded water gives rise to a band at $1420-1650 \mathrm{~cm}^{-1}$ observed in the HA-1 powder and vanished after the sintering process for HA-1 microspheres. The presence of the $\mathrm{CO}_{3}^{2-}$ group is observed in the HA-1 powder and lost in the spectra of microspheres, which suggests that $\mathrm{CO}_{3}^{2-}$ could be not into the crystalline network but on the surface of the material. This last sample presented higher crystallinity than the original powder material. Both HA-1 and HA-2 materials can be easily recognized as nonstoichiometric HAs. In the spectra of the HA-2 powder, a bands appears at 472 (v2), $563(v 4), 605$, and $960(v 1) \mathrm{cm}^{-1}$ that correspond to the $\mathrm{PO}_{4}^{3-}$ group. On the other hand, bands are present at 1642, 1454 (v3), 1420, and $875 \mathrm{~cm}^{-1}$ due to the presence of carbonate group, which is missing after the sintering process similarly to $\mathrm{HA}-1$ materials. The $\mathrm{O}-\mathrm{H}$ stretching $\mathrm{OH}-$ is observed in the band at 3571 $\mathrm{cm}^{-1}$, and the $\mathrm{O}-\mathrm{H}$ stretch $\mathrm{H}_{2} \mathrm{O}$ is shown in the band $3432 \mathrm{~cm}^{-1}$.

HA-2 microspheres are characterized by sharp, well-resolved bands at 3571, 602, and $571 \mathrm{~cm}^{-1}$. The most intense feature in the IR spectra is the 1041 $\mathrm{cm}^{-1}$ band with some shoulders at 1118, 971, and $945 \mathrm{~cm}^{-1}$, suggesting the presence of two phases; $\mathrm{HA}$ and $\beta$-TCP. The band at $1089 \mathrm{~cm}^{-1}$ corresponds to $\mathrm{P}-\mathrm{O}$ stretching vibrations. The broad bands at 3497 and $1992 \mathrm{~cm}^{-1}$ is due to the presence of both water and structural hydroxyl groups. The bands at 3572 and $633 \mathrm{~cm}^{-1}$ have been assigned to stretching and bending vibrations of the structural hydroxyl group. 


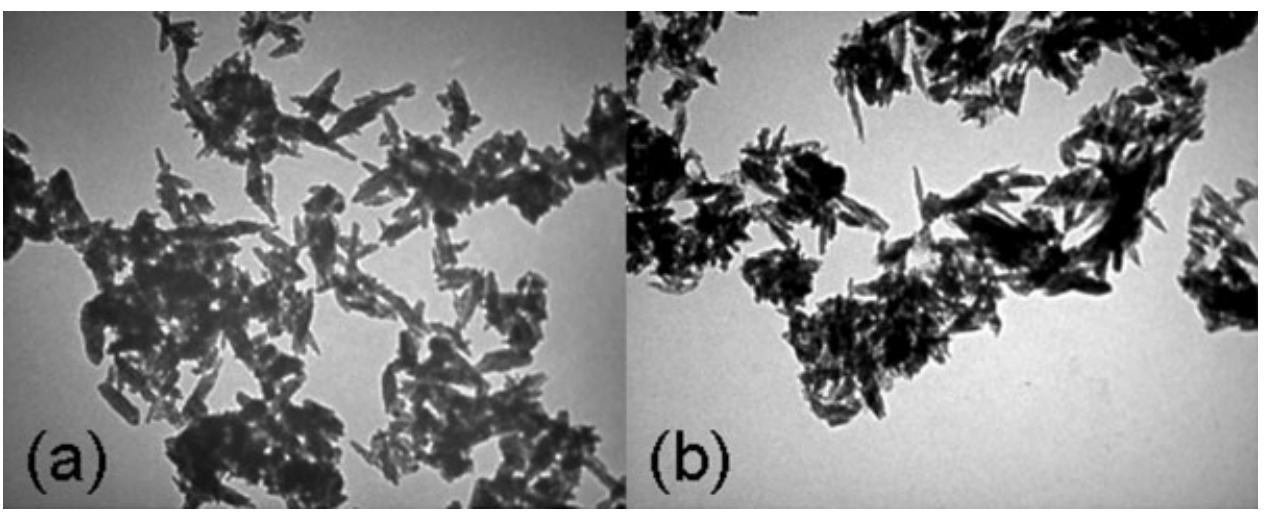

Figure 2. TEM images of HA-1 (a) $\times 20,000$ and HA-2 (b) $\times 20,000$ powders.

Figure 2 shows the morphology of the nanoparticles after the sintering process, of both materials, that generates the microspheres. From TEM images in Figure 2(a,b), some agglomerates of HA and the needlelike shape of the particles in both materials may be seen. HA-1 and HA-2 samples present smaller agglomerates wherein the nanometer size (less than $100 \mathrm{~nm}$ in length) of the HA particles is observed.

The alginate/HA beads were formed by dropping the paste into an aqueous solution of calcium ions. During the sintering process, the alginate was burned off and the HA particles became associated, maintaining the original spherical shape. The aver- age diameter of HA microspheres varied depending on the type of HA used, thus, for HA-1 samples, it was $471 \pm 23 \mu \mathrm{m}(n=20)$; whereas for the HA-2 samples, it was $407 \pm 42 \mu \mathrm{m}(n=20)$. HA-2 microspheres shrank to about $19 \%$ of their original size after the sintering process, whereas the shrinkage for HA-1 microspheres was of about $28 \%$.

SEM images of the microspheres are presented in Figure 3. After the sintering process, their size decreases due to alginate burn-off, even though their original shape is maintained. HA microspheres are depicted in Figure 3(a,b) illustrating their spherical shape as well as their uniform size. Higher surface roughness is evidenced in HA-2 microspheres when
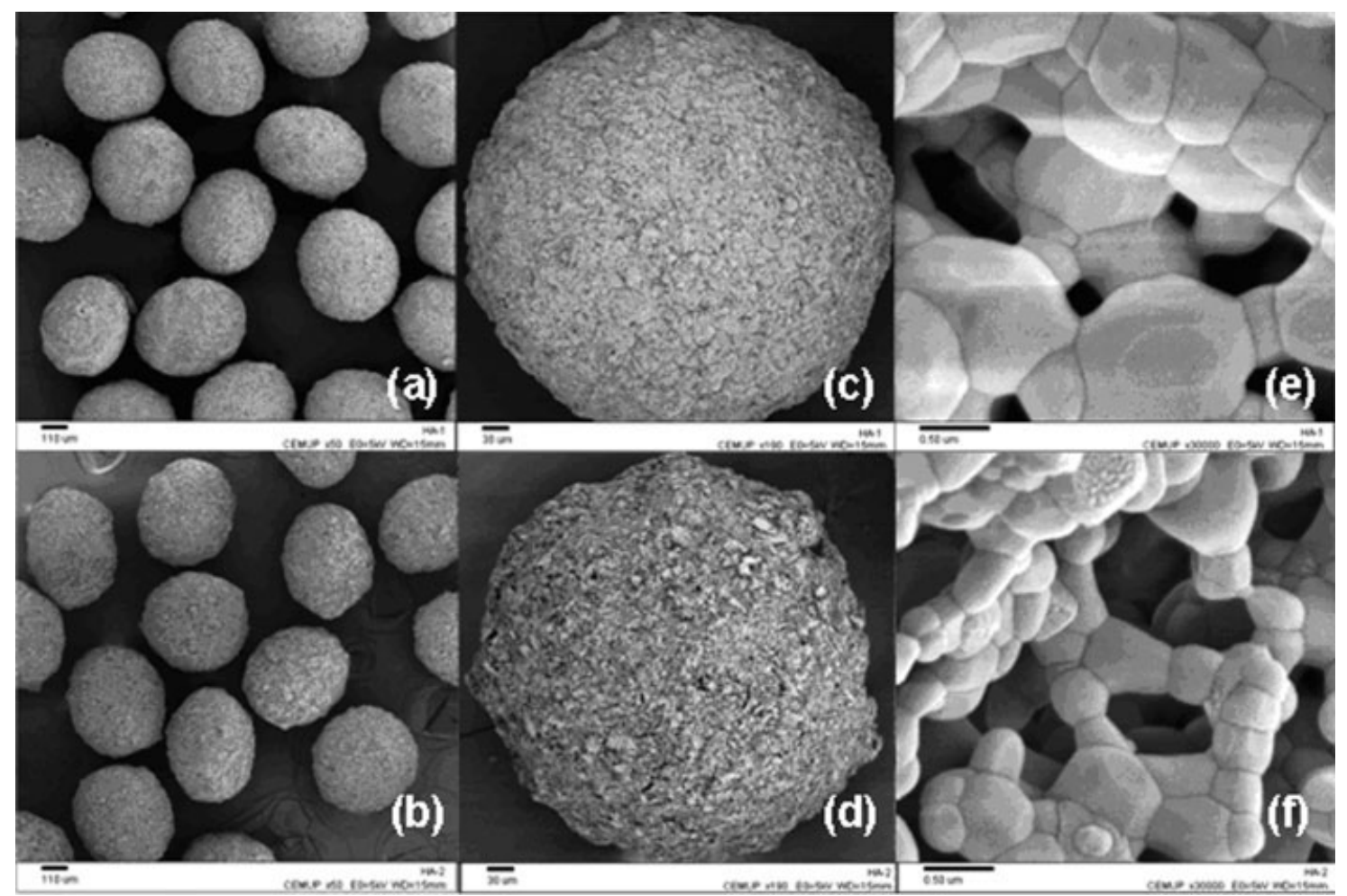

Figure 3. SEM micrographs of HA-1 $(\mathrm{a}, \mathrm{c}, \mathrm{e})$ and HA-2 (b,d,f) microspheres: $(\mathrm{a}, \mathrm{b}) \times 50 ;(\mathrm{c}, \mathrm{d}) \times 190$; and $(\mathrm{e}, \mathrm{f}) \times 30,000$. 
TABLE I

Mercury Porosimetry

\begin{tabular}{lll}
\hline \multicolumn{1}{c}{ Determinations/Samples } & HA-1 & HA-2 \\
\hline Diameter average $(\mu \mathrm{m})$ & 0.5311 & 0.8211 \\
Pore volume $(\mathrm{cc} / \mathrm{g})$ & 0.1507 & 0.1876 \\
Pore surface area $\left(\mathrm{m}^{2} / \mathrm{g}\right)$ & 0.4958 & 0.5444 \\
Pore number fraction & 0.00196 & 0.00336 \\
Total surface area $\left(\mathrm{m}^{2} / \mathrm{g}\right)$ & 1.9308 & 1.4023 \\
Apparent density $(\mathrm{g} / \mathrm{cc})$ & 1.7653 & 1.6726 \\
Total intraparticle porosity $(\%)$ & 45.063 & 47.571 \\
Theorical porosity $(\%)$ & 45.052 & 45.871 \\
\hline
\end{tabular}

compared with HA-1 [Fig. 3(c,d)]. Interconnectivity seems to be higher in HA-2 than in HA-1 microspheres. This can be due to the thickness of the walls that surround pores [Fig. 3(e,f)].

Data obtained from mercury intrusion porosimetry analysis, which are in line with the above results (Table I), do not show significant differences between both types of microspheres related to the pore surface area, apparent density, or total intraparticle porosity. Porosity does not appear to be a significant HA-2 feature in comparison with HA-1 microspheres, however, evident differences about diameter, pore volume, and pore fraction number are found, all being higher for HA-2.

XRD patterns of all samples are shown in Figure 4. HA-1 powder is represented by the pattern in Figure 4(a) and some undefined humps can be seen, because of the nonsintered state. Figure $4(a, c)$ presents many similarities even though after the sintering process they revealed the presence of different phases. The pattern in Figure 4(b) shows clearly the peaks corresponding to pure monoclinic HA, however, Figure 4(d) shows a mixture of monoclinic HA and $\beta$-TCP.

In this work, the cytotoxicity tests of HA microspheres were performed using human MG-3 osteoblast-like cells line. Results presented in Figure 5 showed that there is continued growth during the culture time using both HA-1 and HA-2 microspheres. Cells seeded on TCPS, used as a control, showed the same trend, but with a higher growth rate than both microspheres. The control presented less number of viable cells in the first day probably due to the less available surface area compared to the microspheres. The HA-1 microspheres presented a slight increment in the number of viable cells in comparison with HA-2 microspheres at the end of the culture, and higher growth rate as well.

SEM images of MG-63 osteoblast cells cultured for 7 days on the surface of HA- 1 and HA-2 microspheres based on nanosized HA are presented in Figure 6 . The surface of both HA-1 and HA-2 microspheres is almost completely covered by layers of cuboidal cells, which became denser along the entire time of culture, forming confluent monolayers. Cells built bridges between neighboring microspheres (HA-1 and HA-2 microspheres) forming microspheres-cells clusters (see Fig. 7). CLSM images in Figure 8 show HA-1 and HA-2 microspheres uni-

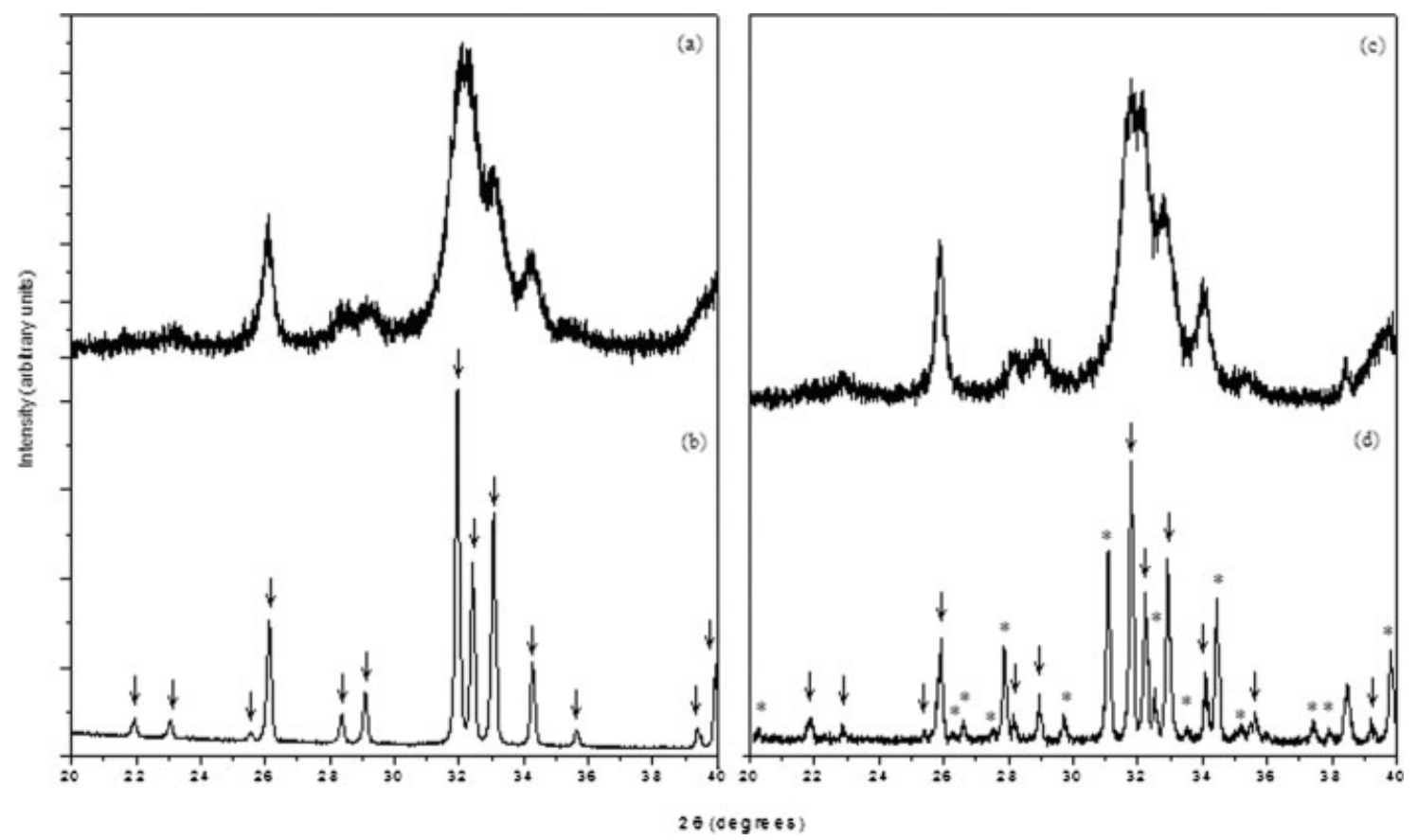

Figure 4. X-ray diffraction of powders and microspheres of HA-1 and HA-2. (a) HA-1 powder, (b) HA-1 microspheres, (c) HA-2 powder, and (d) HA-2 microspheres. 6: monoclinic HA, *: $\beta$-TCP. 


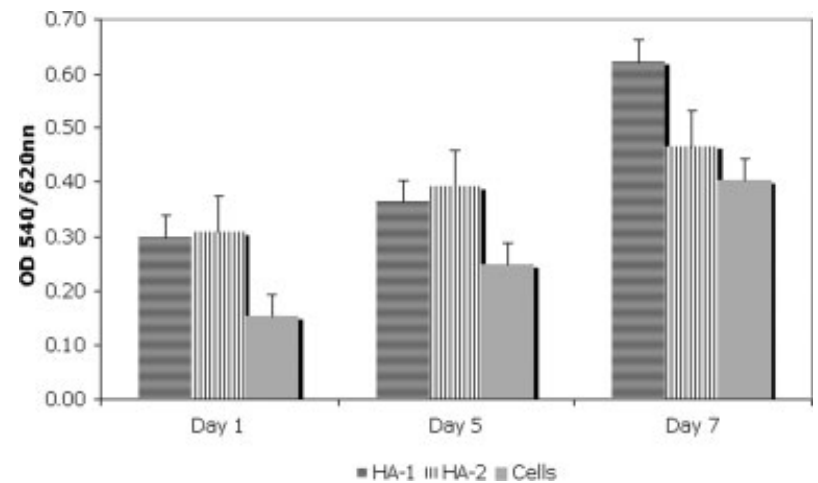

Figure 5. MG-63 cells culture on microspheres based on hydroxyapatite nanosized.

formly colonized by osteoblasts cells after 5 days of culture.

\section{Statistical analysis}

Data are presented as mean \pm standard deviation $(n=5)$, and they were analyzed using the Student's $t$ test for independent samples. Differences between groups were considered statistically different when $p<0.05$.

\section{DISCUSSION}

In this work, nanoHA microspheres synthesis was carried out, using two different types of nanosized $\mathrm{HA}$, and a subsequent characterization at morphological and physical level was performed. HA micropheres were prepared using the droplet extrusion process combined with ionotropic gel formation in the presence of calcium ions. The methodology used to prepare HA microspheres has a remarkable advantage as it allows the preparation of sphericalshaped particles with an adequate and uniform size. ${ }^{34,36-39}$

The microspheres described in this work are composed of two types of HA nanoparticles, both processed by chemical precipitation, and differing in the SDS addition. The synthesis of HA can take place through a variety of processes. One such method is the wet chemical route, wherein HA is precipitated from either an acid-based reaction or a reaction between various salts. Among the different synthesis methods, the wet or precipitation method of synthesizing HA has proved to be popular and for this reason this preparation method has been extensively published. The chemical precipitation method involves the addition of phosphate ions to a solution

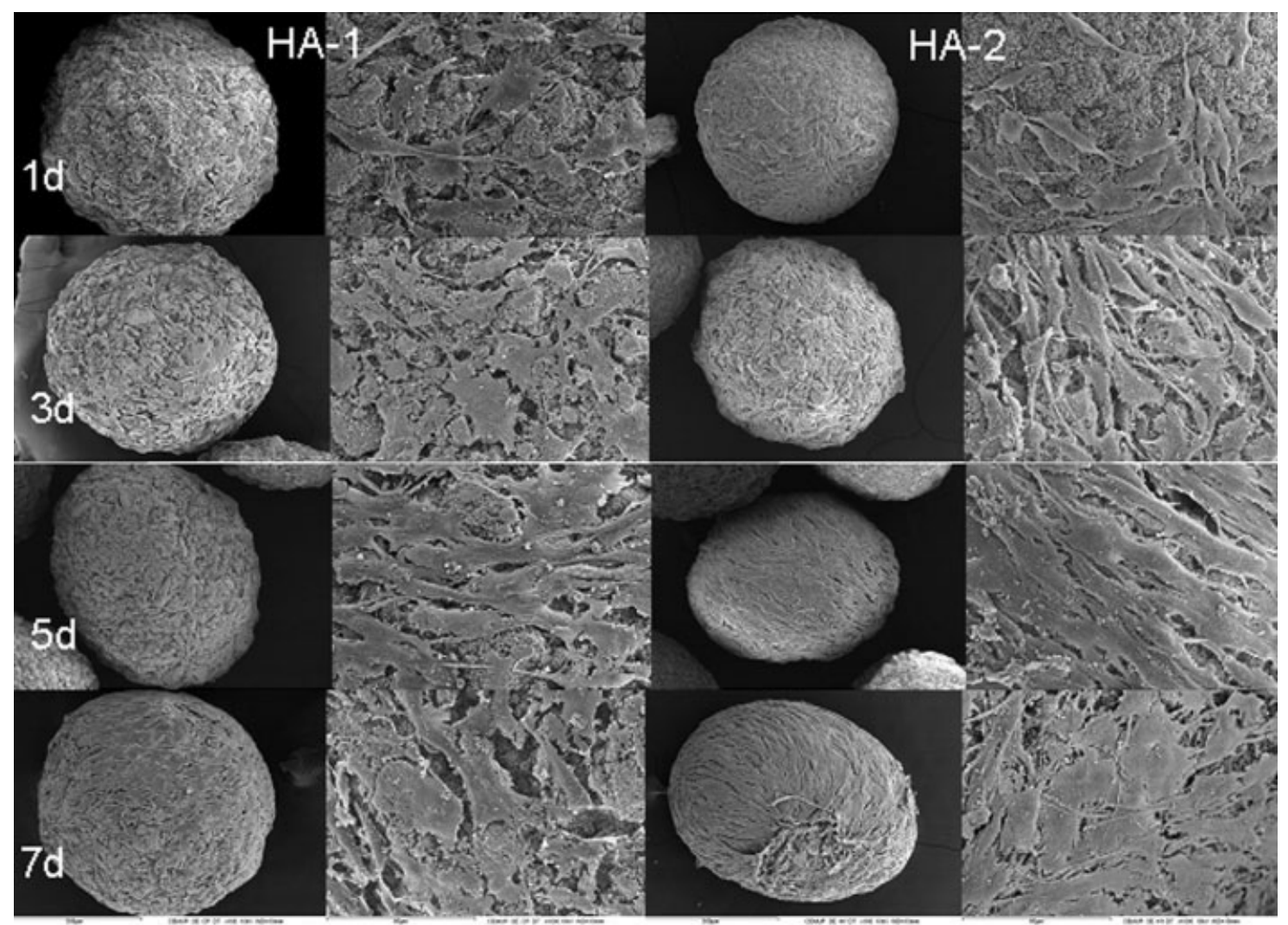

Figure 6. SEM micrographs of 1 to 7 days of MG-63 cells culture on microsphere HA- 1 and HA-2 $(\times 180$ and $\times 1,000)$. 


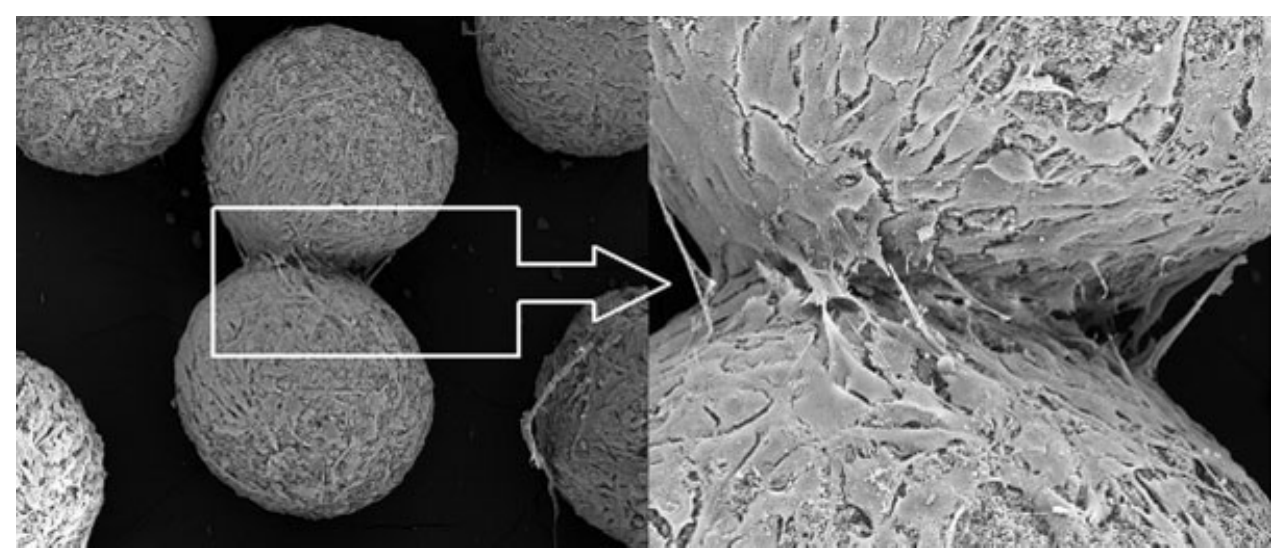

Figure 7. SEM micrographs (left: $\times 110$ and right: $\times 1,000$ ). Notice that osteoblast cells built bridges between neighbor microspheres. This image corresponds to HA-1 construct after 3 days.

of calcium ions, thereby precipitating HA as well as other calcium phosphates such as $\beta$-tricalcium phosphate $(\beta-\mathrm{TCP})$.

Many chemical processing routes have been employed to prepare fine and agglomerate-free ceramic HA. For that reason, several dispersants have been successfully used to prepare HA particles ${ }^{40,41}$ with smaller size and higher surface area. ${ }^{42}$ In this work, a surfactant (SDS) assisting the chemical precipitation method is found to be able to promote the formation of nanosized HA crystal and at the same time control the agglomeration of particles.

Sodium dodecylsulfate (SDS- $\mathrm{C}_{12} \mathrm{H}_{25} \mathrm{NaO}_{4} \mathrm{~S}$ ) is an ionic surfactant and probably the most researched anionic surfactant compound. The molecule has a tail of 12 carbon atoms that attached to a sulfate group, giving the molecule amphiphilic properties. In this study, SDS could have worked by disrupting bonds interparticles, thereby deagglomerating them.
Also, anions of SDS could effectively impart a negative charge on the particles and create an electrostatic repulsion creating more isolate particles. This same fact could explain the presence of two different phases in the HA-2 material based on SDS: the electrostatic repulsion could have limited the complete reaction between reagents and favor the production of $\mathrm{C}_{10}\left(\mathrm{PO}_{4}\right)_{6}\left(\mathrm{OH}_{2}\right)$ and $\beta-\mathrm{Ca}_{3}\left(\mathrm{PO}_{4}\right)_{2}$. Furthermore, the presence of SDS into the calcium phosphates preparation could have filled some spaces that after the burn-out process were empty, creating higher porosity and interconnectivity in HA-2 more than in HA-1 microspheres [Fig. 3(e,f)].

Even though the roll played by SDS in the production of HA-2 material is still unknown, it is not part of the aim of this work and it will need further studies.

The characterization analyses included FTIR, TEM, SEM, mercury porosimetry, and XRD and in vitro

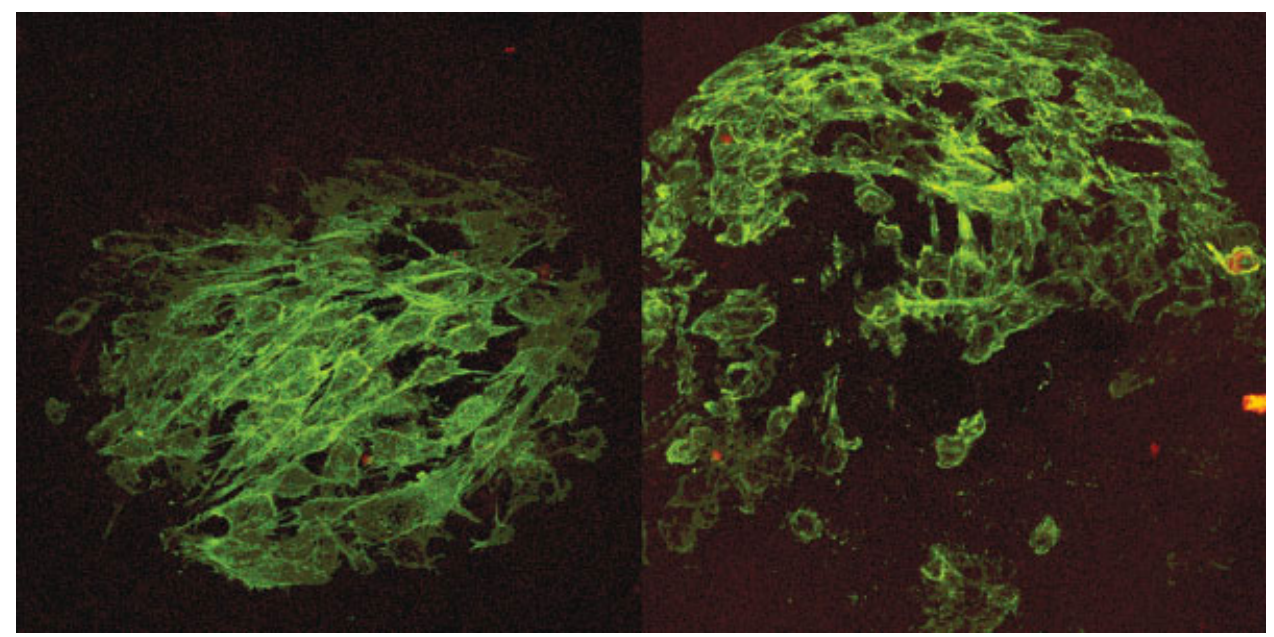

Figure 8. CLSM images of HA-1 (left: $\times 100)$ and HA-2 (right: $\times 100)$ microspheres after 5 days of MG-63. [Color figure can be viewed in the online issue, which is available at www.interscience.wiley.com.] 
tests. FTIR analysis indicated that the characteristic spectra bands of both ceramics, HA-1 and HA-2 powders, are maintained in the microspheres, suggesting the sodium alginate did not induce subsequent modifications in the ceramics structures, for instance, the addition of $\mathrm{CO}_{3}^{2-}$ group, may be due to alginate, in the HA lattice, probably due to the fast sintering cycle, which provides higher porosity in comparison with longer cycles, or it may also derive from the contact with the atmosphere during HA processing. Therefore, alginate may have played two roles in the microspheres preparation: as a vehicle to form spherical-shape particles and as pores inducing agent in the sintering process, all of this without any modification on HA. It is important to point out the multiple-binding sites on the microsphere surface that could allow the attachment of certain macromolecules such as enzymes or antibiotics, among others. This feature may enhance its role as a drug-delivery system component to be used in biomedical applications.

Attractive advantages such as avoiding the use of organic solvents of difficult removal, the manufacturing spherical particles with uniform size, and the possibility of producing particles with different porosities $^{28,36}$ are some characteristics related to microspheres prepared using the method referred here. Besides, in this work, nanophasic HA was used to prepare microspheres what caused a diminution of diameter and therefore a lower surface area; in contrast to previous studies where micrometric commercial HA and calcium-titaniumphosphate (CTP) were used as raw materials. ${ }^{34}$

The use of nanostructured HA in the microspheres introduced a new question mark about how the bone cells would behave when in contact with this new type of microspheres, since the existing literature related to microspheres based on nanosized particles is scarce. Even though, recent works have indicated the benefits of using nanoHA in several biomaterials different to microspheres. To follow some few examples, adhesion of osteoblasts on nonfunctionalized with RGD nanoparticulate calcium phosphate was similar to the conventional HA functionalized with $\mathrm{RGD}^{43}$; fibrous scaffolds fabricated by electrospinning from polycaprolactone (PCL) solutions containing nanoparticles of HA promoted much better adhesion and proliferation of cells than the corresponding $\mathrm{TCPS}^{44}$; biocompatibility testing of nanoparticles dispersed within a viscous polysaccharide (dextran sulfate) porous sponge showed retention of human bone marrow stromal cells viability, production of extracellular matrix, and alkaline phosphatase expression ${ }^{45}$; investigations about the effect of nanometer HA on the proliferation and osteogenic differentiation of periodontal ligament cells showed that nanoHA has ability to promote the activity of osteogenetic differentiation for periodontal ligament cells when compared with the dense HA. ${ }^{46}$

The cell culture o fMG-63 tests carried out in this work aimed at analyzing possible differences in behavior resulting from the significant changes in HA crystallites size, and at comparing the two types of material, HA-1 and HA-2 as substrates for cells.

The present studies suggest that the features such as composition and roughness can modulate osteoblast responses to these scaffolds in vitro, including cellular proliferation, attachment, and threedimensional structure of the forming osteoblast multilayer network. Differences in composition (nanophasic HA and HA/ $\beta \mathrm{TCP}$ ) and evident roughness (see Fig. 3) higher in HA-2 than HA-1 are the most relevant characteristics, since pore diameter or porosity do not present significant differences.

After 7 days of culturing, the distribution of cells over the HA microspheres appeared similar, suggesting that the cells on both HA-1 and HA-2 were proliferating with cuboidal and well-attached morphology colonizing uniformly both type of microspheres, even though HA-1 microspheres presented a slight increment in the number of viable cells in comparison with HA-2 microspheres at the end of the culture as well as higher growth rate.

Albeit, several authors ${ }^{47-49}$ have shown that surface roughness is an important parameter in the basic biologic responses improving cell attachment and proliferation; in this study, HA-1 microspheres presented slight higher cell viability than HA-1, whereas HA-2 microspheres presented higher roughness than HA-1. This fact could be related to the composition (HA but $\mathrm{HA} / \beta-\mathrm{TCP}$ ) revealing that this, the chemical composition, would have higher influence than the roughness on the cellular response.

\section{CONCLUSIONS}

Preparation and initial characterization of two different types of HA nanosized microspheres (HA-1 and HA-2) intended to be used as drug-delivery systems, and bone regeneration matrixes were studied in this work. SEM images showed that MG-63 cells, cultured for 7 days, attached and spread through the available surface of these two types of porous microspheres with some orientation, exhibiting adequate osteoblasts morphology. Neutral Red assay results revealed higher cell viability in the HA-1 than in HA-2 microspheres.

A.Y. Pataquiva Mateus is grateful to the Portuguese Foundation for Science and Technology (FCT) for awarding her a scholarship (SFRH/BD/16616/2004). 


\section{References}

1. Jarcho M. Calcium phosphates ceramics as hard tissue prosthetics. Clin Orthop Relat Res 1981;157:259-278.

2. Bucholz R, Carlton A, Holmes R. Hydroxyapatite and tricalcium phosphate bone graft substitutes. Orthop Clin N Am 1987:18:323-334.

3. Daculsi G, Passuti N, Martins S, Deudon C, LeGeros R, Raher $\mathrm{S}$. Macroporous calcium phosphate ceramic for ling bone surgery in humans and dogs: Clinical and histological study. J Biomed Mater Res 1990;24:379-396.

4. Gauthier O, Bouler J, Weiss P, Bosco J, Daculsi G, Aguado E. Kinetic study of bone in growth and ceramic resorption associated with the implantation of different injectable calcium-phosphate bone substitutes. J Biomed Mater Res 1999;47:28-35.

5. Rey C. Calcium phosphate biomaterials and bone mineral: Differences in composition, structures and properties. Biomaterials 1990;11:13-15.

6. Yuan H, Kurashina K, de Bruijn J, Li Y, de Groot K, Zhang $X$. A preliminary study on osteoinduction of two kinds of calcium phosphate ceramics. Biomaterials 1999;20:1799-1806.

7. Liou S, Chen S, Liu D. Synthesis and characterization of needlelike apatitic nanocomposite with controlled aspect ratios. Biomaterials 2003;24:3981-3988.

8. Earl JS, Wood DJ, Mile SJ. Hydrothermal synthesis of hydroxyapatite. J Phys Conf 2006;26:268-271.

9. Han JK, Song HY, Fumio S, Lee BT. Synthesis of high purity nano-sized hydroxyapatite powder by microwave-hydrothermal method. Mater Chem Phys 2006;99:235-239.

10. Yoshimura M, Sujaridworakun P, Koh F, Fujiwara T, Pongkao D, Ahniyaz A. Hydrothermal conversion of calcite crystals to hydroxyapatite. Mater Sci Eng C 2004;24:521-525.

11. Bogdanoviciene I, Beganskiene A, Tonsuaadu K, Glaser J, Meyer HJ, Kareiva A. Calcium hydroxyapatite $\mathrm{Ca}_{10}\left(\mathrm{PO}_{4}\right)_{6}$ $(\mathrm{OH})_{2}$ ceramics prepared by aqueous sol-gel processing. Mater Res Bull 2006;41:1754-1762.

12. Liu DM, Troczynski T, Tseng WJ. Water-based sol-gel synthesis of hydroxyapatite: Process development. Biomaterials 2001;22:1721-1730.

13. Bezzi G, Celotti G, Landi E, La Torretta TMG, Sopyan I, Tampieri A. A novel sol-gel technique for hydroxyapatite preparation. Mater Chem Phys 2003;78:816-824.

14. An GH, Wang HJ, Kim BH, Jeong YG, Choa YH. Fabrication and characterization of a hydroxyapatite nanopowder by ultrasonic spray pyrolysis with salt-assisted decomposition. Mater Sci Eng A 2007;449-451:821-824.

15. Varma HK, Babu S. Synthesis of calcium phosphate bioceramics by citrate gel pyrolisis method. Ceram Int 2005;31:109-114.

16. Jarudilokkula S, Tanthapanichakoonb W, Boonamnuayvittayaa V. Synthesis of hydroxyapatite nanoparticles using an emulsion liquid membrane system. Colloids Surf A. Forthcoming.

17. Bose S, Saha SK. Synthesis and characterization of hydroxyapatite nanopowders by emulsion technique. Chem Mater 2003; 15:4464-4469.

18. Nayar S, Sihna MK, Basu D, Sinha A. Synthesis and sintering of biomimetic hydroxyapatite nanoparticles for biomedical applications. J Mater Sci: Mater Med 2006;17:1063-1068.

19. Tas AC. Synthesis of biomimetic Ca-hydroxyapatite powders at $37^{\circ} \mathrm{C}$ in synthetic body fluids. Biomaterials 2000;21:1429-1438.

20. Wanga A, Yina $H$, Liua D, Wub H, Wadac $Y$, Rena M, Xua $Y$, Jianga $T$, Chenga $X$. Effects of organic modifiers on the size-controlled synthesis of hydroxyapatite nanorods. Appl Surf Sci 2007;253:3311-3316.

21. Zhang HG, Zhu Q. Surfactant-assisted preparation of fluoride-substituted hydroxyapatite nanorods. Mater Lett 2005;59: 3054-3058.
22. Liu Y, Houa D, Wangb G. A simple wet chemical synthesis and characterization of hydroxyapatite nanorods. Mater Chem Phys 2004;86:69-73.

23. Pang $Y X$, Bao $X$. Influence of temperature, ripening time and calcination on the morphology and crystallinity of hydroxyapatite nanoparticles. J Eur Ceram Soc 2003;23:1697-1704.

24. Gitzhofer BE, Boulos MI. Morpholgical study of hydroxyapatite nanocrystal suspension. J Mater Sci: Mater Med 2000;11: 523-531.

25. Barbosa M, Granja P, Barrias C, Amaral I. Polysaccharides as scaffolds for bone regeneration. ITBM-RBM 2005;26:212-217.

26. Hari P, Chandy T, Sharma C. Chitosan/calcium-alginate beads for oral delivery of insulin. J Appl Polym Sci 1996;59: 1796-1801.

27. Barrias CC, Ribeiro CC, Barbosa MA. Adhesion and proliferation of human osteoblastic cells seeded on injectable hydroxyapatite microspheres. Key Eng Mater 2004;254-262:877-880.

28. Ribeiro CC, Barrias CC, Barbosa MA. Preparation and characterisation of calcium-phosphate porous microspheres with a uniform size for biomedical applications. J Mater Sci: Mater Med 2006;17:455-463.

29. Bowersock T, Martins S. Vaccine delivery to animals. Adv Drug Deliv Rev 1999;32:167-194.

30. Kong H, Smith M, Mooney D. Designing alginate hydrogels to maintain viability of immobilized cells. Biomaterials 2003;24:4023-4029.

31. Legallais C, David B, Doré E. Bioartificial livers (BAL): Current technological aspects and future developments. J Membr Sci 2001;181:81-95.

32. Liu XD, Yu WY, Zhang Y, Xue WM, Yu WT, Xiong Y, Ma XJ, Chen $Y$, Yuan Q. Characterization of structure and diffusion behaviour of Ca-alginate beads prepared with external or internal calcium sources. J Microencapsul 2002;19(6-1):775-782.

33. Taqieddin E, Amiji M. Enzyme immobilization in novel alginate-chitosan coreshell microcapsules. Biomaterials 2004;25: 1937-1945.

34. Ribeiro C, Barrias C, Barbosa M. Calcium phosphate-alginate microspheres as enzyme delivery matrices. Biomaterials 2004; 25:4363-4373.

35. Kim YJ, Park HG, Yang YL, Yoon Y, Kim S, Oh E. Multifunctional drug delivery system using starch-alginate beads for controlled release. Biol Pharm Bull 2005;28:394-397.

36. Barrias C, Ribeiro C, Lamghari M, Sá C, Barbosa M. Proliferation, activity and osteogenic differentiation of bone marrow stromal cells cultured on calcium titanium phosphate microspheres. J Biomed Mater Res A 2005;72:57-66.

37. Mateus AYP, Ferraz MP, Monteiro FJ. Microspheres based on hydroxyapatite nanoparticles aggregates for bone regeneration. Key Eng Mater 2007;330-332:243-246.

38. Mankani M, Fowler B, Kingman A, Robey P. In vivo bone formation by human bone marrow stromal cells: Effect of carrier particle size and shape. Biotechonol Bioeng 2001;72:96107.

39. Higashi $\mathrm{T}$, Okamoto $\mathrm{H}$. Influence of particle size of calcium phosphate ceramics as a capping agent on the formation of a hard tissue barrier in amputated dental pulp. J Endodoncy 1996;22:281-283.

40. Guo G, Xun Y, Wnag Z, Guo H. Preparation of hydroxyapatite nanoparticles by reverse microemulsion. Ceram Int 2005;331:869-872.

41. Sun XM, Chen X, Deng ZX, Li YD. A CTAB-assited hydrothermal orientation growth of $\mathrm{ZnO}$ nanorods. Mater Chem Phys 2002;78:99-104.

42. Uota M, Arakawa H, Kitamura N, Yoshimura T, Tanaka J, Kijima T. Synthesis of high surface area hydroxyapatite nanoparticles by mixed surfactant-mediated approach. Langmuir 2005;21:4724-4728. 
43. Balasundaram G, Sato M, Webster TJ. Using hydroxyapatite nanoparticles and decreased crystallinity to promote osteoblast adhesion similar to functionalizing with RGD. Biomaterials 2006;27:2798-2805.

44. Wutticharoenmongkol P, Sanchavanakit N, Pavasant P, Supaphol P. Novel bone scaffolds or electrospun polycaprolactone fibers filled with nanoparticles. J Nanosci Nanotechnol 2006; 6:514-522.

45. Gonzalez-McQuire R, Green D, Walsh D, Hall S, ChaneChing J, Oreffo ROC, Mann S. Fabrication of hydroxyapatite sponges by dextran sulphate/amino acid templating. Biomaterials 2005;26:6652-6656.

46. Sun WB, Wu YF, Ding Y, Chu CL, Liu TJ. The expression and activity of alkaline phosphatase in human periodontal ligament cells with nanometer hydroxyapatite. Zhonghua Kou Qiang Yi Xue Za Zhi 2006;41:348-349.

47. Bowers K, Keller JC, Randolph B, Wick D, Michaels C. Optimization of surface micromorphology for enhanced osteoblast responses in vitro. Int J Oral Maxillofac Impl 1992;7:302-310.

48. Martin JY, Schwartz Z, Hummert TW, Schraub DM, Simpson J, Lankford J Jr, Dean DD, Cochran DL, Boyan BD. Effect of titanium surface roughness on proliferation, differentiation, and protein synthesis of human osteoblast-like cells (MG63). J Biomed Mater Res 1995;29:389-401.

49. Boyan BD, Batzer R, Kieswetter K, Liu Y, Cochran DL, Szmuckler-Monclers S, Dean DD, Schwartz Z. Titanium surface roughness alters responsiveness of MG63 osteoblastic-like cells to $1 \alpha, 25-(\mathrm{OH})_{2} \mathrm{D}_{3}$. J Biomed Mater Res 1998;39:77-85. 